\title{
Reflexive Textuality: Researcher as Fractured Context
}

\author{
Dennis S. Erasga \\ Behavioral Sciences Department, De La Salle University-Manila, Philippines
}

\begin{abstract}
Ethnography is a form of reading in its postmodern sense. This is a methodological principle the present paper attempted to demonstrate. By analyzing an ethnographic work written by a Filipina anthropologist about a religious community in the Philippines, the author generated several rules concretizing a research methodology he called reflexive textuality. This approach transforms investigators into readers of both text and context. The basic assumption however, is that whether the investigators are reading texts and/or contexts, their interpretive engagement extends to and matters most in, the actual writing of their textual outputs. Thus, reflexive textuality does not only involve contextualizing a text (i.e., interpreting a text via its context), but also textualizing a context (i.e., converting context into a readable text). In the latter, the multiple and fragile positions a researcher invokes and brings into play while writing his/her ethnography ultimately displace the authentic context of the data set initially co-produced and co-interpreted with research participants. The paper ends with some notes on the implications of reflexive textuality as a qualitative research approach.
\end{abstract}

KEYWORDS: Text, mimesis intertextuality, reflexive textuality, reader-centered criticism, fractured context

Ethnography is a method of studying and learning about a person or group of people ${ }^{1}$ (see Vidich \& Lyman, 1998). Typically, ethnography involves the study of a small group of subjects in their own environment. Rather than looking at a small set of variables and a large number of subjects (i.e., the big picture), ethnographers attempt to get a detailed understanding of the circumstances of the few subjects being studied. Ethnographic accounts, then, by nature are descriptive and interpretive. Descriptive, on the one hand, because empirical data (e.g., thick descriptions) are crucial and required. On the other hand, it is interpretive because the ethnographer must determine the significance of what s/he observes without gathering broad, statistical information.

The interpretive side of ethnographic writing, nonetheless, provokes serious epistemological tensions especially within the context of the debates engendered by newer methodologies being tested in qualitative types of researches. For one, it is now being acknowledged that writing as a creative process requires a different set of competence on researchers (Lim, 2002; Tate, 1997; Guba \& Lincoln, 2000) as the context of the weaving (or creative) process shifts- from the immediate context (i.e., the field) to the effective context (i.e., 
the researchers themselves) (Erasga, 2004). This interpretive dimension of the writing act, I think, is made even more complicated by the postmodern transformation of the field work as a form of context reading and as such, requires an engagement between what is being read and its reader. Together, these epistemological nexus of reading and writing as intertwined creative processes are manifestations of what Flick (2002) referred to as the "mimetic transformation" moments of text production and reception (p. 92).

These issues are the loci of the present article. Using an ethnographic work of a Filipina anthropologist as an excursus, I will demonstrate that (i) ethnography writing involves mimetic processes which transform the investigator into a reader not only of texts, but also of contexts; that (ii) reading and writing are intertwined creative moments that necessitate the invocation of multiple and oftentimes, fragile contexts; and (iii) that researchers themselves are fractured contexts given the multi-situated positions they take into account as narrative weavers thus influencing the degree of their interpretive engagement with the text before them. ${ }^{2}$ Cabanilla's (1999) work is chosen because of the centrality of the notion of intertextuality- the nexus between text and context, of meaning and interpretation- in her ethnographic work about a religious community in Batangas $^{3}$, Philippines.

Three caveats are in order. First, it will be obvious to readers that my overall approach to Cabanilla's work takes the form of a critique. As a critique, however, I appraise her entire ethnography as a 'methodological treatise.' Hence, the focal point of my interpretive gaze is not on the specific findings articulated in her text but on the epistemological themes and issues her methodological approach brings to the fore. Said differently, I am more interested in the epistemological repercussions of the methods she employed than on the methods themselves. However, it should be emphasized that Cabanilla's limitations as a writer is occasioned by her medium, e.g. a dissertation and by her distance from the members of the community who produces the first level interpretation.

Second, the word text is used in this paper in a variety senses. Conventionally it refers to scribed documents to wit: (i) the ethnographic work of Cabanilla (the dissertation itself) and (ii) the source document she used in producing the latter- the written narrative authored by one of the members of the religious community she studied. Inside double quotation marks, "text" assumes its postmodern meaning- anything that could be read including written documents, interaction episodes, physical set-up, conversation, and even contexts for that matter.

Lastly (and as a form of limitation) the principles generated from the analysis of Cabanilla's work need to be strengthened by taking in more ethnographic works with similar ethos or of the safe genre. As such, the generalizability of reflexive textuality as a methodological perspective may be appreciated without being accused as anecdotal. This paper is only an initial and partial attempt to articulate what I believe are recent critical issues in qualitative social science research.

\section{ORGANIZATION OFTHE PAPER}

I organize my discussion in three parts. Part 1 presents a brief description of Cabanilla's opus focusing on the plot of her ethnographic account of a local religious community in Batangas including brief descriptions of the community in terms of its mission and of the text Cabanilla used as 'source document.' The second part outlines my evaluation of the implications of her methodology especially her notion of intertextuality. In this section, I designate 'Cabanilla as a reader' bounded by rules, expectations and competencies governing a reader as she makes sense of her "texts". Expectedly, I include a discussion of two abiding issues related to text production (ethnography in particular) namely: (i) reading as a world-making moment and (ii) text as empirical material. Both are contentious fragments of the concept of mimesis implicated in recent debates in qualitative research approaches. 
They serve as background to the third and last part which zooms in on key epistemological implications of my particular interpretation of Cabanilla's work such as the issues of representation and audienship. Here, I develop and expound on the methodological technique called reflexive textuality and the potentiality of its promises as a qualitative research perspective.

\section{CABANILLA'S WORK IN A GLIMPSE}

Daylinda Banzon-Cabanilla is a cultural anthropologist currently teaching at the University of the Philippines, Los Banos. Her choice of dissertation topic and the interest to pursue it was spurred by her unexpected encounter with Roma Manalo- the granddaughter of the founder of a Tagalog religious community known as Kapisanang Sagrada Familia ("Community of the Holy Family" hereinafter referred to as Kapisanan). The meeting took place in 1989 at the site (i.e., Dampalit, Los Banos, Laguna) where one of Cabanilla's undergraduate classes was conducting a field research. It was during that time, Cabanilla recounted, that Roma's religious group was struggling to establish a branch in that area.

A religious community, Kapisanan proclaims that God has abandoned the idea of sending messengers (six individuals from six generations have been sent: Noah, Abraham, Jacob, Moses, Jesus Christ). Instead, He came to earth Himself in the person of Amang Andres Manalo [Father Andres Manalo, the seventh generation]. Thus, he and his descendants is believed to comprise the Holy Family. Kapisanan is based in various places in the province of Batangas, where their seven kaharian (kingdom) are located: Bagong Monte de Oro, Bagong Roma, Bagong Herusalem, Bagong Palestina, Bagong Judea, Bagong Ehipto, and Bagong Babilonia (Cabanilla, 1999).

One that qualifies as narrative analysis, Cabanilla's entire ethnographic project hinges on a source document - the Mahiwagang Kasaysayan ("Secret History", hereinafter referred to as Kasaysayan) authored by Roma Manalo in
1988. After several encounters, spread over a year, and for reasons unknown to Cabanilla, Roma gave the only copy of the Kasaysayan to her. As the title implies, the Kasaysayan is a mythical rendition of the history of the Philippines juxtaposing the lives of Maria Makiling - the resident goddess or goddess protector of Mount Makiling in Los Banos, Laguna and Jose Rizal- a celebrated Tagalog hero who lived during the Spanish period. Kasaysayan narrates the country's "mysterious history - how the Encantadores [elementals] particularly Maria Makiling and Jose Rizal figured prominently in the events leading to the execution of Rizal and the eventual liberation of the Philippines from Spain's powerful influence particularly on religion" (p. 6).

As a rationalization for the existence of the Kapisanan and of her authorship (Roma's) this text proves to be a religious narrative from its very first paragraph:

Ito and Testamento de los Testamiento del Mundo na ayon sa antas ng kaisipang malawakan na tumatalakay sa kaalamang hango sa likas at pansariling karunungan. Binanatay nito ang likas na Kapangyarihan ng Kataas-taasang manglalalang at lumikha ng lahat ng kabuoan ng sangkatauhan at sanglibutan na siyang hukom na taga hatol sa lahat ng bagay at sinuman. [This is the Testament of all Testaments of the World that is according to the degree of the broad mind that discusses the knowledge derived from inherent and personal intelligence. This is justified by the natural Power of the Most High creator and maker of all the wholeness of humanity and the world who is the judge that gives judgment to all things and anyone.]. (Cabanilla, 1988, p. 6)

Given the origin, nature and content of the Kasaysayan and Kapisanan, Cabanilla deciphers Kasaysayan via its "narrative features and construction" highlighting the triplet issues of author, authorship, and authority. As a story, Cabanilla toys 
with the key elements of characters and plot treating the entire text as a religious discourse. As a sacred community, she analyzes the Kapisanan in terms of its rituals and as the context of Kasaysayan. Invoking her version of intertextuality as the interface of text and context, she interprets three powerful ideologies of the Kapisanan namely magic, gods, and gender. The textual discourse approach is triggered by her original conviction that Mahiwagang Kasaysayan "would be a major key to open the doors to understanding the Sagrada Familia." (p. 6)

\section{CABANILLAAS A READER}

I would like to propose a convention that would serve as the canon of my critique of Cabanilla's ethnography. Since her project decidedly focused on text and intertextuality, I would like to designate Cabanilla more as a reader than as a writer of meanings. This designation of Cabanilla as a reader is an essential convention given the nature of what she proposes to accomplish in her research from her data source(s) to the methodological procedures she employs.

As a reader, her hermeneutic ${ }^{4}$ stance is circumscribed by certain expectations and competence of a reader. ${ }^{5}$ With this, I invoke some basic assumptions of the reader-centered criticism as applied in social research. Called with different labels, ${ }^{6}$ reader-centered criticism interrogates the responsibility of the reader from a passive role to a very active one. Hence, the locus and actualization of meaning may be rendered problematic as it was once assumed to be not. According to Lim (2002) reader-oriented criticism:

...is more interested in the process than the outcome. Meaning is not inherent in the text but emerges only as the reader enters into dialog with the text. Meaning lies in the adjustment and in the readers' revision and expectation. It does not come neatly packaged in the text. ${ }^{7}$ (p. 35)
At this juncture, two critical issues involving reading and writing as intertwined modalities of text production need to be clarified namely (i) reading as a world-making moment and (ii) text as empirical material.

\section{Reading: A World-Making Moment}

Reading is neither an innocent act nor a passive activity. According to literary critics such as Suleiman \& Crosman (1980) the act of reading is concerned with the experience whereby individual readers realize a text. On this note he writes:

The act of reading was defined as essentially a sense-making activity, consisting of the complementary activities of selection and organization, anticipation and retrospection, the formulation and modification of expectations in the course of the reading process. (Suleiman, 1980, pp. 22-23)

So in reading a book, one is actually engaging in the events of the mind of the writer. Both are bringing their creative faculties into synchronize. The reader imagines the words, the sounds of the words, while thinking of the various characters in terms of people s/he has known not in terms of the writer's experience but his/ her own (Plimpton 1988). At this ontological level, it is quite difficult to make any distinction between reader and writer. Perhaps this is the reason why Morrison (1993) is swayed by the thought that "text by their very nature are not impervious to varying interpretations, and as a result, they are ultimately not the text written by their authors, but those read by their readers" [italics added] (p. 3).

\section{Text as Empirical Material}

Given such nature of reading as a creative and dynamic process, the implication on the very nature of texts becomes equally contentious. An emerging trend in qualitative research is the imputation of a new nature on text as empirical material. Texts in this regard are considered versions of the world and hence, reflections of social reality. This 
perspective on the nature of text radicalizes the traditional conception of text as being only a representation of reality. In qualitative research, this translates to the idea that text is no longer a vehicle of reality, but in itself is a "substantiated reality."

Such evolved nature of textual (or scribed) materials is based on two burgeoning conceptualizations of how texts are produced- both of which are expressions of what Garz and Kraimer (1994) allude to as the increasing "textualization of the world." The first one is suggested by Gebauer \& Wulf's (1995) rendition of the Aristotelian mimesis; the other is a signature idea in Fairclough's (1999) critical discourse analysis (or CDA).

Mimesis refers to the conversion of natural worlds into symbolic worlds. As articulated by Aristotle, it is understood as imitation of nature. Imported into the qualitative social research discourse, mimesis is conceived of as "a general principle with which to map out one's understanding of the world and of text" (Flick, 2002 , p. 33). It is through mimetic processes that the individuals assimilate themselves to the world and embodies such assimilations in various forms. Hence, "mimesis makes it possible for individuals to step out of themselves, to draw the outer world into their inner world, and to lend expression to their interiority" (Gebauer \& Wulf, 1995 cited in Flick, 2002, p. 33).

Importing these mimetic gestalts to qualitative research (specifically to texts used in such research), mimetic elements are discernible in the following process:

(i) in the transformation of experience into narratives, reports, etc. on the part of the person being studied; (ii) in the construction of texts on this basis; (iii) in the interpretation of such construction on the part of the researchers; and (iv) finally when such interpretations are fed back into everyday contexts, for example in reading the presentations of these findings. (Flick, 2002: 33)
Hence, writing and reading texts are active and intertwined processes of producing reality involving not only the author of the text, but also the person who reads (i.e. who analyzes and interprets) the text. Within the context of qualitative research, this interface implies that in the making of texts (on a certain subject, an interaction, or an event, or an experience) "the person who reads the written text is as equally ontologically involved in the construction of reality as the person who writes the text.

Mimetic processes then impute texts with empirical nature as valid and as fresh as those data taken from personal interviews, focus group discussions, surveys, or from field observation. Textual mimesis elevates the status of texts from secondary reference to empirical data. As again Flick (2002) posits:

This substantiation of reality in the form of texts is valid in two respects: as a process which opens access to a field and, as a result of this process, a reconstruction of the reality which has been textualized. The construction of a new reality in the text has already begun at the level of the field notes and at the level of the transcript and this is the only (version of) reality available to the researcher during his or her following interpretations. (p. 174)

In arguing for the inclusion of textual analysis as part of the methodological armory of social science, Fairclough (1999) cites four important features and functions of texts as empirical materials. According to him (i) text is an important form of social action; (ii) texts constitute a major source of evidence for grounding claims about social structures, relations and processes; (iii) texts are sensitive barometers of social processes, movement and diversity, and social change; and lastly, (iv) it is increasingly through texts that social control and social domination are exercised (and indeed negotiated and resisted).

Fairclough's conceptualization of texts may not capture the full force of the mimetic gestalt discussed above. However, his argument for the increasing textualization of the social world makes texts not only ubiquitous but also as a simulacrum 
of the social. Simulacrum is an intriguing concept articulated by Baudrillard (1988) referring to the blurred distinction between the real thing and its representation. He argues that in postmodernity it is no longer possible to make a distinction between the real and the unreal: "images have become detached from any certain relation to the real world with the result that we now live in a scopic regime dominated by simulations, or simulacra" (Rose, 2001: 8).

Applying the mimesis trends in social research, texts become the simulacra of human expressions and social interactions. Actions, thoughts, feelings and even interactions are textualized (e.g., Internet chat, teleconferencing, and fax messages) and serve as representation of human experience- that is- writing on the part of the author, and reading on the part of the reader. Nothing is not converted into texts, hence the call of Fairclough for a more serious attention to textual materials as empirical facticity.

\section{What and How Does Cabanilla Read?}

Mimetic transformation, therefore, annihilates the pesky distinction between reading and writing as two separate interpretive episodes in text production. The seamless connection between reading and writing help explain the intriguing nature of Cabanilla's ethnography. At this point, I would like to expand our understanding of this fusion by proposing that: ' how Cabanilla reads is largely conditioned by what she reads in the first place.' That is, the type of reading she employs is determined by what she believes to be her textual materials. The question then to ask is: what did she read? A passage from her text suggests an answer:

Indeed, with the text [i.e., the Kasaysayan] as the center, my field engagement with Roma and the Sagrada Familia became its context. Roma herself in her 'Introduction' underscored the importance of this context to the construction and content of her text. Thus while the focus of my ethnography is now Roma's
Mahiwagang Kasaysayan, I cannot escape a consideration of the holy community where she is positioned because such a contextualization is critical for our exploration of not only her identity but also the site of meaningfulness of her mythic text. (p. 119)

With this passage, she admits reading Roma's text as well as the context that lends significance to its content and her identity as its author- the Sagrada Familia. Going back to her account as to how she analyzes and interprets this text, she declares that Roma's text (which was in her possession for quite a while and with which she did not know what to do) suddenly becomes meaningful when juxtaposed to her interpretive community. Therefore, Cabanilla is able to break through her source text by invoking Kapisanan in her reading not only as the context of the text, but as the context of her reading. Theoretically speaking, these are two different modes of reading and in doing both synchronically Cabanilla casts a much wider epistemological net by converting both into readable "texts." ${ }^{8}$ To explicate this point, it would be useful to introduce Hall's (1980) typology of readings. ${ }^{9}$

Hall (1980) enumerates three types of readings a viewer may actively construct from a particular text. These include a "dominant" (hegemonic or preferred) reading, a "negotiated" reading and an "oppositional" reading. A dominant reading concedes to the text's worldview without question, while a negotiated reading consents to the worldview informing the text at the same time, however, challenging some of the text's ideological underpinnings. As a result, negotiated readings are often saturated with contradictions, though these are only on certain occasions brought to full visibility. Finally, an oppositional reading begins from an alternative framework of reference that fundamentally rejects the text's ideological assumptions since they support a system the reader opposes. $^{10}$

Interestingly, the common thread that broaches the Hallian trichotomy of readings is the active engagement between the text and its reader. 
Engagement is a term frequently employed in discussions of reception and is generally associated with Hall's (1980) article "Encoding/Decoding" in which he argues that all readings are negotiated to some degree rather than simply passed on by the text to passive-receptive viewers.

Based on the above typology of readings, Cabanilla as a reader swings between the hegemonic and negotiated readings. Hegemonic, in the sense that in reading Roma's texts, she follows the direction of Roma's discourse (or hagiography) including the meaning system shrouding the personalities she encountered and rituals she observed; negotiated because her reading of the meanings of some typical and even erratic observations are informed by her respondents' interpretation of the meaning systems. The hegemonic reading is evident in her complete dependence on Roma's text; while the negotiated reading is evident in her conversion of text and context into readable "texts." The following passage is illustrative of these somewhat ambivalent positioning:

... for whatever reason, Mahiwagang Kasaysayan fell into my hands from heaven, so to speak. Invitation to other rituals followed soon after. My family and I attended the ritual in Bagong Herusalem [New Jerusalem] .... We joined the Holy Week overnight trek to the caveshelters in the mountains of Simlong where amulets were recharged with magical powers....We attended also the wedding ritual for Palestina [Roma's younger sister]....In all of these interactions, I found a dearth of direct explanations, some transparent explication of the meanings that filled the rituals and the more everyday kinds of activities and behavior [italics added]. I was lost in another world. I remember my predicament when I first encounter Roma's father, Amang Salvador who was considered the most 'senior' among the seven sibling gods, I did not know how I was supposed to greet god: how was I, a nonmember, expected to behave face-to-face with god? (Cabanilla, 1999, pp. 4-5)
Surprisingly, her reading modalities ultimately have had repercussions on the dynamic modes of meaning-production she employs while collecting her field data and while composing her ethnography. As in the oscillating modalities of reading she employs, collecting field notes and making sense of these notes are two knotty episodes in the postmodern research praxis. Generally, they are issues in interpretation as an act of producing meaning.

\section{ISSUES IN INTERPRETATION AS MEANING PRODUCTION}

As a reader Cabanilla brings to the fore critical issues in qualitative research methods. For convenience and focus, I limit the issues into twoon representation and on reflexive textuality both of which are connected with how qualitative researchers generate meaning and how they interpret their observations as they compose their written outputs.

\section{Representation and Audienceship}

By the word representation in this critique I refer to the attempts of ethnographers to depict the nature of the subject matter and research subjects. Representation by its very nature does more than represent reality; it constructs reality. According to Lyon (1997) "an ethnography is a representation of complexity that ideally allows readers to make some sense of the whole by focusing on significant parts- that is a rather artificial exercise which requires construction" (p. 68). Hence representation is an issue in so far as the researchers may portray a flawed picture of the research subject by constructing an alternative one (Lehtonen, 2000). At this juncture, Cabanilla's ethnography makes me realized one important thing vis-à-vis representation- the role of the preconceived audience / reader in text production.

With this, representation could be a tricky modus operandi since the writers' depiction of 
their subject may be influenced by a host of factors ranging from their (writers') political, disciplinary, and most importantly, by the preconceived audience. When ethnographers write, they do have their target audience in mind. The mode and the language of their ethnographies jibe with the competence and demands of these target audience(s). Hence, if the target audience is the ethnographer' research subjects, representation must subscribe to the demands of the subject/ reader but at the expense of the subject being described.

Cabanilla, in this regard, is not clear as to what audience she has in mind. She seems to vacillate between the Kapisanan, her family and her interpretive community- the university academic community, and herself. To her surprise though, members of Kapisanan attempted to abduct the audienceship as revealed by this curious passage from Cabanilla's text:

Their audiovideo tape and photoprint documentation of the ritual provoked great interest not only among my family and friends but also among Roma's Sagrada Familia who, upon viewing the good-quality photodocumentation, immediately pronounced that we (my family) were the chosen ones whose mission was to reveal the real god to the world [italics added]. Others, they said, had attempted but failed to record their voices and images. (Cabanilla, 1999, 4)

The final output, nonetheless, makes it categorical who the real audience Cabanilla had in mind. The textual language subscribes to the demands and semantic competence of her own interpretive community - the academic scholars. As an academic output, it is apparent that the audience she has in mind is, first and foremost, her Graduate Committee and second, the imagined community of scholars who will be reading her work. In this regard, Cabanilla did a wonderful work. One may take note of how she transforms her readings into the prose of her interpretive community - the 'activities' of the Kapisanan into "rituals," their "unequal relations' into "power" relation; their "beliefs' into "ideology," their 'sacred items' as "artifacts," and so forth.

\section{Reflexive Textuality}

As I have mentioned elsewhere in the paper, it is Cabanilla's notion of intertextuality that I find quite interesting. Intertextuality to her is the interface between text and context and not between texts. Take note how she clarifies this notion:

In a broad sense, any ethnography is a study of intertextuality.....In my case I delimit 'text' operationally to refer to Roma's document, and consider the surrounding circumstances of her authorship and authority with the Sagrada Familia as 'context,' but certainly my objective of discovering the relationship between text and context is an intertextual quest. I have narrated my effort to explore Roma's text in the hope of deriving the meanings of the more puzzling context, thus reversing the usual text-context link. However, the designation of what is 'text' and what is 'context' is arbitrary and reversible; text is context, and context is text. Thus, the text-context connection is best described by intertextuality.... In this sense, my entire ethnographic enterprise; while restricted to a particular delimited text and context can be subsumed under the tile of intertextuality [italics added]. (p. 181)

Her intertextual quest must have been based, I suspect, on her training as an anthropologist- a training that takes as given the methodological rule that 'a text has no meaning apart from its context.' It is interesting to note though that as a reader Cabanilla fuses the text and its context into a whole new fabric- a new text for that matter! In doing so, Cabanilla did not just contextualize a text (e.g., Roma's text) as demanded by the traditional ethnographic canon. Rather, she also textualized a context (e.g., Kapisanan). Either way, she is 
able to transcend the limitation of Roma's text in acquiring meaning for itself by invoking its context (i.e., the Kapisanan) and examined the same as a readable text.

However, as a reader, Cabanilla fails to fully reckon her position as a reader of text and context. This suspicion is made obvious by her assumption that the nexus between text and context is a contingent one. In the preceding quote, she believes that Roma's text necessarily (and automatically) becomes readable once linked to the author's sacred community. She fails to recognize her active part in facilitating the nexus; in assuring that the relationship between her text and context is bridged. If not for her intervention as reader, the meaning of Roma's texts, - derived from the Kapisanan - could not have been realized.

Phrased differently, intertextuality as the intersection of text and context is only a virtual potentiality. Without the reader, intertextuality could not become a reality. To incorporate the creative role of the reader in guaranteeing intertextuality, I propose a concept that captures such dynamics between texts and context as bridged by the reader. I call it reflexive textuality. It is reflexive in three significant senses: First, because authors are also readers in a sense (that is, they are authors cum readers) - analogously suggestive of the mimetic dialectic between writing and reading as creative episodes. Second, authors cum readers navigate back and forth in their "texts," which mean that while writing they read both text and contexts as a unified material. And finally, it is reflexive because the terminal point of the mimetic/ interpretive process is the author himself/herself and his/her nuanced positions.

\section{REFLEXIVE TEXTUALITY: SOME METHODOLOGICAL IMPLICATIONS}

My primary goal in writing the present paper is to generate useful methodological insights from my critique of Cabanilla's work. With this end in mind,
I identify two insights: (i) the locus of meaning and (ii) the fractured contexts. The former has already been articulated and made famous by the American literary theorist, Crosman (1980) in his discussion of the possible meanings of the word "meaning;" the latter operationalizes my own notion of shifting contexts. Both, nonetheless, are significant in understanding how researchers themselves become the effective but highly fractured context of their ethnographic projects.

\section{Locus of Meaning, Fractured Contexts}

In explicating the notion of fractured context, I would like to use the concept of locus of meaning in reading texts. Locus of meaning has bearing on the very issues raised by Cabanilla with regards to meaning and interpretation. According to Chandler (1995) meaning emerges in the relationship between readers and texts. Table 1 presents the locus of meaning as a continuum between two extreme positions.

With reference to Table 1, we could generate two types of context invoked by the researchers in different episodes: the observing and composing contexts. Observing context refers to the situation where authors as readers collect, analyze and interpret their field data together with their research participants. It is the context where the two parties co-construct the data to be collected and co-actualize the meanings of those data (cf. Oerter, 1999). It is in the observing context, then, that both researchers and their subjects are constructive agents.

Composing context, on the other hand, is epistemologically different from the observing context. It refers to the circumstances surrounding the actual writing moment of the ethnography. Here the researcher as reader is the sole constructive agent in the production of meanings from the collected data. Since the researchers are not always conscious on the conceptual distinction between the two as they produce their ethnographies, they invoke them in a precarious and arbitrary manner. This being the case, researchers can be fractured contexts themselves. 
Table 1.

Locus of Meaning in the Reading of Texts

\begin{tabular}{lll}
\hline Objectivist & Subjectivist & Constructivist \\
\hline meaning is entirely in & meaning is in interplay & meaning is entirely in \\
text and is & between text and reader & its interpretation by \\
and is $-----\rightarrow$ & reader and is \\
'transmitted' & 'negotiated' & 're-created' \\
reader as less "passive," more "active"
\end{tabular}

Note. This is Chandler's (1995) rendition of how a reader makes sense of the meanings s/he creates in every textual encounter (i.e., reading). I extend his position by arguing that this situation is equally true when $\mathrm{s} / \mathrm{he}$ is writing.

Juxtaposing the above discussion in Cabanilla's case, we could conclude that when she was in the field her observing context includes the materials she covered including the named and unnamed people of Kapisanan and Roma's textKasaysayan. Note, too, that the amount and kind of data she is able and allowed to collect are circumscribed to a significant extent by the level of involvement of her field participants (Cabanilla, 1999). Thus, the meanings of her observations / data derived are from her interpretation of these data tempered by that of her respondents. In this sense, she is a subjectivist and she admits this:

Perhaps I am like some ethnographers who establish more than academic....relationships with our subjects of study, and discover that our personal selves are entangled in our study. I developed emotional attachments in the course of my study: the date when Roma wrote her text, I noted, was exactly the month and year when my father died. I was very moved by the rituals that I attended; .... Above all, I harbored a very strong feeling that there was a purpose to my meeting Roma and her Sagrada Familia, and that this reason would serve to integrate my personal and professional selves. That is how and why I now launch this postmodern project of understanding
Mahiwagang Kasaysayan, Roma and her Sagrada Familia, my anthropology, my self, and my social world. (Cabanilla, 1999, 8-9)

But while formally composing her ethnography she unconsciously shifts context altogether. Within the writing moment her context has been exclusively herself - a woman, an anthropologist, a university professor, a mother, and a graduate student. A new context has taken over, that is, the observing context has been superseded by the composing context. Hence, the gamut of meanings she produces from her source document and field notes are already displaced (or perhaps muted) by her multiple positions largely as a situated academician. As a matter of fact, this context displacement accounts for how she transforms her data into something very different from the meaning system she originally created/negotiated with her research participants. In these senses, Cabanilla as a reader is a constructivist. Notice how she deconstructs the data and from there produce different outputs:

Based on my encounter with Roma, I have tried some ways of understanding my data: [italics added] from presenting a professorial chair lecture on ethnoarcheology of the sect artifacts to writing a brief prospectus for class 
in anthropological research methods. And now I experiment on another way through this dissertation.... (Cabanilla, 1999, p. 8)

Cabanilla's swinging from being a subjectivist to constructivist is not a sign of any methodological dodginess as it may initially suggest. Curiously, such interpretive ambivalence is a hallmark of qualitative approaches in general and of reflexive textuality in particular. In the same vein, we could say that when ethnographers compose their texts, they constantly oscillate position from one extreme to another (and maybe back), that is, from a co-producer of meanings to a solipsist. The interesting part of this fractured hermeneutic positioning is the realization that ethnographers as writers have shifting interpretive contexts the most germane of which is their multiple locations as they navigate from field to paper. To use reflexive textuality as a research approach is to incriminate ourselves as partial and highly opportunistic creative textual agents. This is a sociological reality we researchers of the social have to contend with.

\section{CONCLUSIONS}

In doing the critique, I realize the changing nature of ethnography and its production. Ethnography apparently is no longer exclusively connected with brute facts, of thick description. Rather it could take various forms from field observation to text to context reading. As such, the traditional epistemic distinction between reading and writing as two mutually exclusive episodes of ethnography production is thus rendered problematic.

A corollary conclusion I draw from this paper pertains to the role of the researcher as narrative weaver. That is, is the researcher remains, at the end, the hegemonic agent in the interpretation of observations and actualization of meanings. No amount of interpretivism could reduce such authorial power as a reader and writer of "texts." Phrased differently, the researcher may initially, at one level (i.e., during data collection) co-negotiate meanings with his/her research participants. However, at the composing moment, it is the researcher who constructs the final texture of the outputs. The changing conceptualization of the nature of context provides the answer for this.

Context can no longer be conceived as a setting in the strictest sense of the word. Cabanilla's case interrogates such traditional rendition of context as 'background.' Her work elevates the utility of 'context as background' into something equivalent to a readable text, which as such may form part of the data from where meanings can be 'generated' by researchers, thus making context as part of the ethnographic data itself.

This changing nature of writing ethnography visà-vis context as readable text are operable only in conjunction with the idea that researchers do not cease to be readers of contexts but are ambivalent and highly fractured contexts themselves. Hence intertextuality may no longer be limited to the interface of text and context as Cabanilla poignantly demonstrates. Rather it extends to and matters most at the crossing point between the reader and his/her text. This postmodern principle is reminiscent of the blurred distinction between reading and writing as intertwined creative episodes in text production.

\section{NOTES}

\footnotetext{
${ }^{1}$ I should admit that ethnography both as a concept and practice has been defined in so many different ways by different authors. Massey (1998) for example outlined the litigious aspects of ethnography writing from the kind of data to collect, to the variety of methods of doing it, to the role of the ethnographers themselves in the field. Therefore, the definition I offered here emphasizes its descriptive and interpretive dimensions if only to capture the debates shrouding its praxis.

${ }^{2}$ This is what Tate (1997) might have meant with the phrase "conversation between the world of the text and the world of the reader" ( $p$. xxiv). Text here refers to either a document being read or a narrative being written.

${ }^{3}$ The province of Batangas is 110 kilometers south of and is about $11 / 2$ hours ride away from Manila.
} 
${ }^{4}$ Longman (1987) suggests that the terms hermeneutics and interpretation can be used interchangeably as both refer to the process of determining the meaning and significance of a text (see also Gomes, 1996; Porter 1990).

${ }^{5}$ The word reader here denotes a postmodern connotation. Reading as an interpretive activity goes beyond mere plowing of words, or what we call as passive reading. As Tate (1997) argues "the reader brings to the text a vast world of experience, presuppositions, methodologies, interests, and competencies. (p. xxiii)

${ }^{6}$ It goes with some of these names: New criticism, readerresponse, reader-oriented, and so forth.

${ }^{7}$ Porter (1990) summarizes the basic tenets of the readercentered approach (i) the center of authority is shifted from the text itself or author to the reader, (ii)readers are involved in a complex interplay with the text which chronicles his/ her struggles to comprehend it, (iii) meaning is not a single thing, which means that meanings of text is not inherent but produced or actualized, (iv) meaning produced as a result of interaction cannot be checked against any objective standard but is a product of reading strategy, (v) those who hold to similar reading strategy constitute an interpretive community.

${ }^{8}$ Conversion of context as readable text is consistent with postmodernism- an epistemological movement which construes everything as a text-hence, they "seek to locate meaning rather than to discover it.... They offer readings not observations, interpretations not findings." (Rosenau, 1992, p. 8 as cited in Gubrium, 1997, p. 75; see also Neuman, 1997)

${ }^{9}$ Should not be confused with the phrase "modes of reading" I used. Hall's typology of reading is based on the position assumes by the readers versus the text before them; my typology is based on the point of reference used by the readers vis-à-vis the text before them.

${ }^{10}$ This is quite similar to Althusser's (1968, trans. 1970, p. 28-9) "symptomatic reading." An interpretive strategy that searches not only for the structural dominants in a text but most importantly, for absences and omissions that are an indication of what the dominant ideology seeks to repress, contain or marginalize. Reading against the grain operates under the assumption that the text comprises a hierarchy of discourses in which one discourse- patriarchal ideology- asserts its dominance over others. (Kotsopoulos, 2006)

\section{REFERENCES}

Althusser, L. (1968, trans. 1970). Reading capital. London: New Left Books.

Baudrillard, J. (1988). Simulacra and simulations. In J. Baudrillard (Ed.), Selected writings (pp. 166184). Stanford, CA: Stanford University Press.
Cabanilla, D. (1999). Text, context and interpretation: The Mahiwagang Kasaysayan and Kapisanang Sagrada Familia. Unpublished doctoral dissertation, University of the Philippines, Los Banos. Laguna, Philippines.

Chandler, D. (1995). The active reader. [online]. Available: http://www.aber.ac.uk/media/ Modules/MC10220/active.html. [September 26, 2006].

Crosman, R. (1980). Do researchers make meaning? In S.R. Suleiman \& I. Crosman (Eds.), The reader in the text: Essays on audience and interpretation (pp. 149-178). Princeton, NJ: Princeton University Press.

Erasga, D.S. (2004). A critique of Daylinda Bazon-Cabanilla's 'Text, Context and Interpretation:The Mahiwagang Kasaysayan and Kapisanang Sagrada Familia.' Unpublished manuscript, University of the Philippines-Los Banos, College of Arts and Sciences.

Fairclough, N. (1999). Linguistic and intertextual analysis within discourse analysis. In A.

Jaworski and N. Coupland, (Eds.), The discourse reader (pp. 183-211). London: Routledge.

Flick, U. (2002). An introduction to qualitative research. London: Sage.

Garz, D. \& Kraimer, K. (Eds.). (1994). Die welt as text. Zur theorie, kritk und praxis der objectiven hermaneutik. Frankfurt a. M.: Suhrkramp.

Gebauer, G, \& Wulf, C. (1995). Mimesis: culture, art and society. Berkeley, CA: University of California Press.

Gomes, P. (1996). The good book: Reading the Bible with mind and heart. New York: William Morrow and Company.

Guba, E. G. \& Lincoln, Y. S. (2000). Competing paradigms in qualitative research. In N. K. Denzin \& Y. S. Lincoln (Eds.), Handbook of qualitative research (pp. 105-117). Thousand Oaks: Sage.

Gubrium, J. \& Holstein, J.A. (1997). The new language of qualitative method. Oxford: Oxford University Press. 
Hall, S. (1980): Encoding/decoding. In Centre for Contemporary Cultural Studies (Ed.), Culture, media, language: Working papers in cultural studies, 1972-79 (pp. 128-38). London: Hutchinson.

Kotsopoulos, A. (2006). Reading against the grain revisited. Jump Cut: A Review of Contemporary Media. [Online serial]. Available: http://www.ejumpcut. org/archive/ jc44.2001/aspasia/ againstgrain1.html.

Lehtonen, M. (2000). The cultural analysis of texts. Thousand Oaks: Sage.

Lim, J.T.K. (2002). A strategy in reading biblical texts. New York: Peter Lang.

Longman, III T. (1987). Literary approaches to biblical interpretation. Grand Rapids. MI: Zondervan.

Lyon, E. (1997). Applying ethnography. Journal of Contemporary Ethnography. 26:1.

Massey, A. (1998). The way we do things around here: The culture of ethnography. Paper presented at the Ethnography and Education Conference, Oxford University Department of Educational Studies (OUDES), 7-8 September. [Online paper]. Available: http:// www. geocities.com/Tokyo/2961/ waywedo.htm. (November 29, 2006).

Morrison, T. (1993). Playing in the dark: Whiteness and the literary imagination. New York : Vintage Books.
Neuman, L. (1997). Social research methods. New York: Allyn and Bacon.

Oerter, R. (1999). The measurement of cognitive structures: A constructivist approach. Social Science Information, 38(4), 659-681. London: Sage.

Plimpton, G. (Ed.). (1988). Writers at work: The 'Paris Review' interviews. Harmondsworth: Penguin.

Porter, S. (1990). Why hasn't reader response criticism caught on in New Testament studies? Journal of Literature and Theology, 4-3, 278-292.

Rose, G. (2001). Visual methodologies: An introduction to the interpretation of visual materials. Thousand Oaks, CA: Sage.

Suleiman, S.R. \& Crosman, I. (Eds.). (1980). The reader in the text: Essays on audience and interpretation. Princeton, NJ: Princeton University Press.

Tate, W.R. (1997). Biblical interpretation: An integrated approach. Peabody, MA: Hendrickson Publishers.

Vidich, A.J \& Lyman, S.M. (1998). Qualitative methods: Their history in sociology and anthropology. In N.K. Denzin and Y.S. Lincoln (Eds.), The landscape of qualitative research: Theories and issues (pp. 41-110). Thousand Oaks, CA: Sage. 